\title{
Evaluation of the Influence of Fibre Aspect Ratio and Fibre Content on the Rheological Characteristic of High Yield Pulp Fibre Reinforced Polyamide 11 "HYP/PA11" Green Composite
}

\author{
Robenson Cherizol1,2,3*, Mohini Sain ${ }^{1,3}$, Jimi Tjong2 \\ ${ }^{1}$ Centre for Biocomposites and Biomaterials Processing, Faculty of Forestry, University of Toronto, \\ Toronto, Canada \\ ${ }^{2}$ Powertrain Engineering Research \& Development Centre, Ford Motor Company, Windsor, \\ Canada \\ ${ }^{3}$ Department of Chemical Engineering \& Applied Chemistry, University of Toronto, Toronto, \\ Canada \\ Email: ${ }^{*}$ Robenson.cherizol@mail.utoronto.ca
}

Received 23 December 2014; accepted 16 January 2015; published 19 January 2015

Copyright (C) 2015 by authors and Scientific Research Publishing Inc.

This work is licensed under the Creative Commons Attribution International License (CC BY). http://creativecommons.org/licenses/by/4.0/

\section{(c) (i) Open Access}

\section{Abstract}

The rheological behavior of composites made with low-density polyamide 11 (PA11) and high yield pulp fibre (HYP) is evaluated. The rheological properties of high-yield, pulp-reinforced biobased Nylon 11 HYP/PA11 composite were investigated using a capillary rheometer. The rheological tests were realized in function of the shear rate for different temperature conditions. The experimental results showed that identically for fibre content and aspect ratio, the shearing effects decreased as the temperature increased; that is, the HYP/PA11 became more non-Newtonian in the higher temperature region, which corresponds to the high pseudoplasticity of the HYP/PA11. At low HYP content, the shear viscosity is expected to increase rapidly with increasing concentrations of the fibres because of the rapidly increasing interactions between particles as they become more closely packed. However, at very high fibre content, random anisotropic structure of the fibres in polymer melts is created. The increase in shear viscosity is greater at lower shear rates, where fibre and polymer molecules are not completely oriented.

\footnotetext{
*Corresponding author.
}

How to cite this paper: Cherizol, R., Sain, M. and Tjong, J. (2015) Evaluation of the Influence of Fibre Aspect Ratio and Fibre Content on the Rheological Characteristic of High Yield Pulp Fibre Reinforced Polyamide 11 "HYP/PA11" Green Composite. Open Journal of Polymer Chemistry, 5, 1-8. http://dx.doi.org/10.4236/ojpchem.2015.51001 
Keywords

HYP/PA11, Rheological Characteristic, Shear Viscosity, Shear Rate

\section{Introduction}

Green-fibre-reinforced thermoplastic composites are in high demand in the automotive, aerospace, and construction industries. Vegetable fibres are biodegradable and renewable, they consume less energy than glass fibres, and consequently they generate less pollution [1]. Other reasons for the high demand for the utilization of green fibres are their low density and good thermal and acoustic properties [2]. Pulp fibres, moreover, do not abrade processing tools [2] [3]. Materials from biological sources regroup natural polymers, so they can be expected to exhibit viscoelastic behavior. Appropriate processing and production conditions for polymer products are determined by their rheological characteristics. Short-fibre reinforced polymer composites are extensively used in manufacturing industries due to their light weight and superior mechanical properties [4]-[6]. Hence, pulp fibre has been used not only for its low lignin content but also for its potential thermal stability and its strong adhesion when bonded with high-temperature engineering thermoplastic polymers [7]-[10]. The high-yield pulp "HYP" fibres derived from hardwood that were used in this study are short semicrystalline fibres.

Various experimental studies have emphasized the investigation of the role of flexibility on fluid viscosity. They concluded that the more flexible the fibres, the more pronounced their effect on the rheological characteristics [9]-[13].

A novel study on the effect of fibre-length distribution on the rheological behavior of castor oil composite showed that at high fibre length the shear viscosity becomes more dependent on shear rate [11] [12]. This behavior is due to elastic deformation of the fibres [13].

Recently, several researchers have investigated the effect of fibre content on polymer melt rheology [14]-[16]. One such study showed an important increase in shear viscosity with increased fibre loading at low shear rates, but only a small increase in viscosity at high shear rates. Another similar study on polypropylene-based long fibre observed an increase in shear viscosity with increased fibre content and fibre length; however, this viscosity increase was very small, which the authors attributed to high shear rates and fibre breakage during processing [17] [18]. Non-Newtonian fluid characteristics such as shear thinning were also observed in these studies.

That said, the literature devoted to experimental studies of the rheology of pulp fibres in reinforced polymer composites is very restricted. This is likely due to the complex nature of these materials, the difficulties encountered during their processing as well as the difficulty of characterizing them rheologically [19]-[25].

Processing technique and conditions have a significant influence on the rheological and overall properties of pulp-fibre-reinforced polymer composites because they dictate the degree of dispersion and distribution of the fibre in the polymer matrix [25]-[28]. Compared to other natural fibres, HYP is more thermally stable in presence of high-melting-temperature engineering thermoplastics (under $180^{\circ} \mathrm{C}$ ) such as PA11, PA6 and PA66.

The aim of this study was to investigate the rheological characteristics of high-yield-pulp-reinforced bio-based polyamide 11 composite. Experiments were mainly carried out by varying therheological testing temperatures, the fibre content and aspect ratio.

\section{Materials and Methods}

\subsection{Materials}

The matrix biopolymer bio-based Nylon 11, density 1.03, MFI 11, was supplied by Arkema, France. Aspen HYP fibers were supplied by Tembec (Montreal, QC). The HYP is the type used in wood-free printing and in writing-paper grades and multiple-coated folding-board grades; fibre length is 0.230 to $0.85 \mathrm{~mm}$. Finally, the pulp-fibre length was reduced by using a mechanical crib in order to investigate the aspect ratio effect on the rheological behavior of the HYP/PA11.

\subsection{Methods}

\subsubsection{Composites Preparation}

The experiment was processed using a Conical Twin Screw Extruder. In the mixing method, the HYP fibre was 
dried at $80^{\circ} \mathrm{C}$ for 6 hours and then added to the corresponding PA11 and well mixed before it was introduced to the extruder. The average temperature of the barrel was $200^{\circ} \mathrm{C}$.

\subsubsection{Effect of Processing Conditions}

Many processing parameters affect the properties of final products. For extrusion, temperature profiles affect the fibre degradation. In addition, screw speed and feeding rate change fibre length, distribution, and orientation. Mechanical properties are the reflection of all these changes. The processing parameters are optimized to obtain the best properties. Table 1 represents the processing parameters for HYP/PA11 used in this study.

\subsubsection{Fibre Content Analysis and Determination of Fibre Length Distribution (Original Fibre Length)}

The samples of the fibre as received from the provider were cut into small pieces and immersed in formic acid for three days. The nylon 11 was dissolved by the formic acid and HYP was left. The wood fibre was filtered and washed with formic acid, then dried in a vacuum oven for four hours. By measuring the weight of composite and fibre, we could calculate the actual fibre content.

HYP fibre length was measured with the Fiber Quality Analyzer (FQA). Fibre was diluted with D.I. water. The diluted fibre entered a thin planar channel. This channel helped to gently orient the fibre 2-dimensionally, so that the fibre could be fully viewed by the camera. The picture taken by the camera was then analyzed by the software to give the fibre length distribution.

\subsubsection{Rheological Properties Measurements}

The rheological measurements of the composites' melt-flow properties of were carried out in a twin-bore Rosand Capillary Rheometer model RH2000. (The standard RH2000 range supports temperatures from $-40^{\circ} \mathrm{C}$ to $500^{\circ} \mathrm{C}$. The standard maximum force applied is $12 \mathrm{kN}$.) The composite samples for testing were cut into very small pieces, then placed inside the barrel and forced down into the capillary with the plunger attached to the moving cross-head. Representative steady-shear viscosity versus high shear rate is presented in the figures below for HYP/PA11, which was processed at the average extrusion temperature of $200^{\circ} \mathrm{C}$. The viscosity of the sample was obtained from steady-shear measurements for different temperature profiles, with the rate ranging from 50 to $5000 \mathrm{~S}^{-1}$. The rheology "viscosity" data presented in this paper thus represent an average value of three measurements.

\subsubsection{Scanning Electron Microscopy}

Studies on the morphology of the composites were carried out using a scanning electron microscope (SEM). The rheological test samples were ruptured by the rheometer and the fracture surfaces were examined. A Hitachi S-800 Scanning Electron Microscope (SEM) was used to study the fracture surface and dissolved HYP-reinforced PA11 composites. The observation conditions were the following: pressure 0.3 mbar, acceleration voltage $15 \mathrm{keV}$.

\section{Results and Discussion}

\subsection{Effect of Fibre Content on the Length and Shape Distribution on High Yield Pulp Fibre Reinforced Bio-Based Nylon Composite}

During the extrusion process, the shear stress applied by the screw breaks the fibres. The resulting fibre lengths affect the ultimate mechanical properties. In spite of the influence of fibre damage and breakage during processing, the initial fibre length in the feedstock determines the fibres' final lengths. It is therefore important to

Table 1. Extrusion temperature profile for 10\%, 20\% and 30\% HYP/PA11, 120 RPM (10\% and 20\%), 130 RPM (30\%) and 10 RPM feed rate.

\begin{tabular}{ccccccccccccc}
\hline & \multicolumn{9}{c}{ Temperature $\left({ }^{\circ} \mathrm{C}\right)$} \\
\hline Zone 1 & Zone 2 & Zone 3 & Zone 4 & Zone 5 & Zone 6 & Zone 7 & Zone 8 & Zone 9 & Zone 10 \\
\hline 200 & 200 & 200 & 200 & 200 & 205 & 205 & 205 & 205 & 205 \\
\hline
\end{tabular}


analyze the initial fibre-length distribution. Table 2 represents the effect of fibre content on the length and shape distribution on high yield pulp fibre reinforced bio-based nylon composite.

The arithmetical length-weighted and weight-weighted values of fibre length were found to be $0.18 \mathrm{~mm}, 0.28$ $\mathrm{mm}$ and 0.51 respectively for the fibres from 30\% HYP/PA11. Most of the fibre lengths lie within the range of 0.2 to $0.52 \mathrm{~mm}$, since crushed pulp was used in this study. To obtain these average fibre lengths, 1500 single fibres were examined. The measured initial fibre length is shorter than the actual length of the fibres company provided.

\subsection{Rheological Characteristics of High-Yield-Pulp-Reinforced Bio-Based Nylon}

Rheological characteristics of the polymer, fibre, and interphasial phases influence the final characteristics of the resultant microstructure of the composite materials; these characteristics in turn affect the mechanical properties of a multiphase polymer-composite system. As obtained from experiment, the shear viscosity as a function of the steady-shear rate of HYP/PA11 at $200^{\circ} \mathrm{C}$ is shown in Figure 1. (As noted, these results are the average of three different experimental tests.)

As noted, the composite material used in the experimental study had an average fibre length of $0.73 \mathrm{~mm}$, and the experiment was conducted at $200^{\circ} \mathrm{C}$. The experimental results showed that the viscosity of HYP/PA11 composite decreases with increasing shear rate. This decrease in the shear viscosity with the increase of the shear rate corresponds to the pseudoplastic fluid characteristic of the composites. This pseudoplastic behavior (also referred to as shear-thinning behavior) as plotted in Figure 1 is mainly influenced by the orientation of the polymer molecules, the agglomeration of the flexible pulp fibre, and the entanglements within the polymer chains in the capillary rheometer. On the other hand, the chain agglomerations are produced simultaneously as one chain is collapsed into another chain. The entanglements that lead to agglomerations of the chains, as well as the entanglements within the chains, are caused by the Brownian motions and low relaxation of HYP fibre. The high shear-thinning behavior obtained for HYP/PA11 can be also associated to the thermal degradation of HYP during the rheological testing and the compounding process. The molten polymers tend to arrange themselves with their major axes in the direction of shear, whereby points of entanglement are reduced. As a result, the viscosity decreases. In other words, in this instance of non-Newtonian flow behavior in polymer melts, the decrease in viscosity when the shear rate is increased by applying load is associated with high shear-thinning behavior and

Table 2. Fibre length distribution of pulp fibre (original fibre length).

\begin{tabular}{cccc}
\hline \multirow{2}{*}{ Fibre } & \multicolumn{3}{c}{ Mean Length (Measured) } \\
\cline { 2 - 4 } Only HYP & Arithmetic $(\mathrm{mm})$ & Length Weight $(\mathrm{mm})$ & Weight Weighted (mm) \\
HYP (10\%) & 0.38 & 0.57 & 0.73 \\
HYP (20\%) & 0.20 & 0.29 & 0.44 \\
HYP (30\%) & 0.20 & 0.29 & 0.43 \\
\hline
\end{tabular}

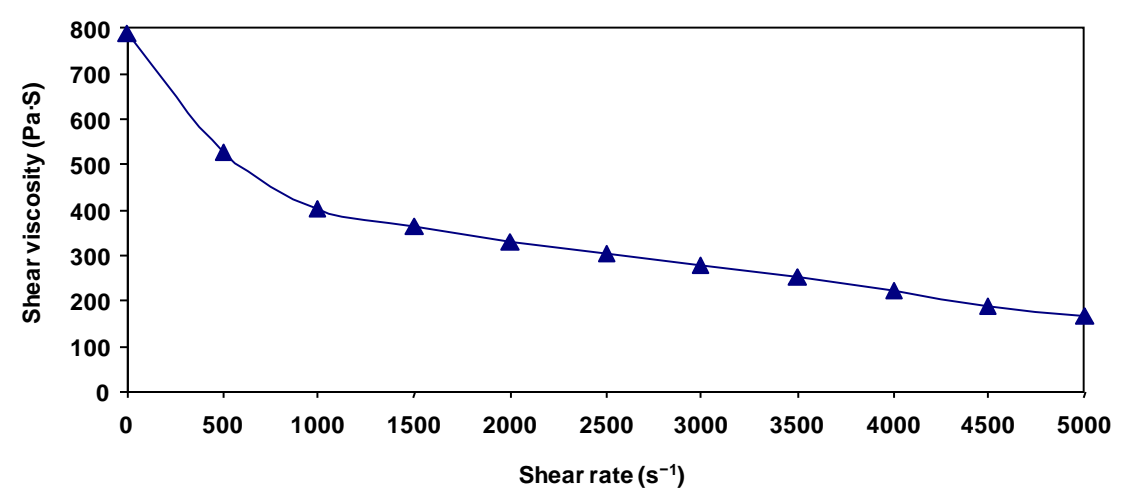

Figure 1. Shear viscosity vs. shear rate of $\mathrm{HYP} / \mathrm{PA} 11$ at $200^{\circ} \mathrm{C}$. 
with viscoelastic characteristics of biocomposite materials. However, at very high shear rates (from 3000 to $5000 \mathrm{~S}^{-1}$ ); the molten HYP/PA11 showed a less restrained decrease in viscosity. This non-Newtonian behavior is associated with the alignment and orientation of the fibre in the polymer chains and the effect of the fibre aspect ratio. Both at low and high shear rates the formation of agglomerates is evident; therefore the pulp molecules are completely oriented due to the good dispersion in the bio-based PA11 matrix. This means that the breakage of the fibre length allows the maintenance of an accurate fibre-aspect ratio when the diameter of flexible HYP is kept unchangeable during the process. The shorter length of the fibres also supports their alignment in the direction of the flow, thus reducing the fibre-fibre collisions and leading to a greater decrease in viscosity.

\subsection{Effect of the Temperature on the Shear Viscosity versus Shear Rate of HYP-Reinforced PA11}

The variation in shear viscosity as a function of the shear rate of HYP/PA11 at various temperatures was investigated and the rheological test results are presented in Figure 2. The rheological conditions were kept constant while different tests were run for $190^{\circ} \mathrm{C}, 200^{\circ} \mathrm{C}$ and $210^{\circ} \mathrm{C}$. The results are presented in the figure below.

The shear viscosity of the HYP/PA11 depended on the rate of shear at which it was measured and presented. The shearing effects decreased as the temperature increased; that is, the HYP/PA11 became more non-Newtonian in the higher temperature region. At higher temperatures the reduction of shear viscosity is more pronounced at intermediate shear rate, while for $190^{\circ} \mathrm{C}$, this reduction is maximized at higher shear rates (from 3000 to $\left.5000 \mathrm{~S}^{-1}\right)$. At low testing temperature $\left(190^{\circ} \mathrm{C}\right)$ and for low and intermediate shear rate, the flow deformation is challenging. This is due to the fact that the HYP-reinforced PA11 fibres are entangled and agglomerated. At this point, such rheological behavior is called near-Newtonian. At high shear rate, the shearing effects increased while the effect of temperature was less pronounced, and flow deformation was mostly dominated by the shearing effect. However, from 3000 to $5000 \mathrm{~S}^{-1}$ all the shear-viscosity variations in function shear rates followed the same rate of deformation for different temperature profiles, which corresponds to shear-thinning behavior.

\subsection{Effect of High Yield Pulp Fibre Content on the Rheological Behavior of HYP/PA11}

The effect of fibre content on the rheological characteristics of the composite was investigated. Figure 3 shows the experimental results for $10 \%, 20 \%$ and $30 \%$ HYPP reinforced polyamide 11 . These curves are typical of pseudoplastic materials, which show a decrease in viscosity with increasing shear rate. At high fibre content, the material offers higher shear viscosity even for high shear rate. In general, the incorporation of fibres in polymer systems increases the viscosity, which rises further as fibre content is increased.

The difference between $10 \%$ and $20 \%$ fibre at intermediate and high shear rate is not very significant. At low HYP content, shear viscosity is expected to rise rapidly with increasing concentrations of fibre because of the rapidly increasing interactions between particles as they become more closely packed. Nevertheless, at very high

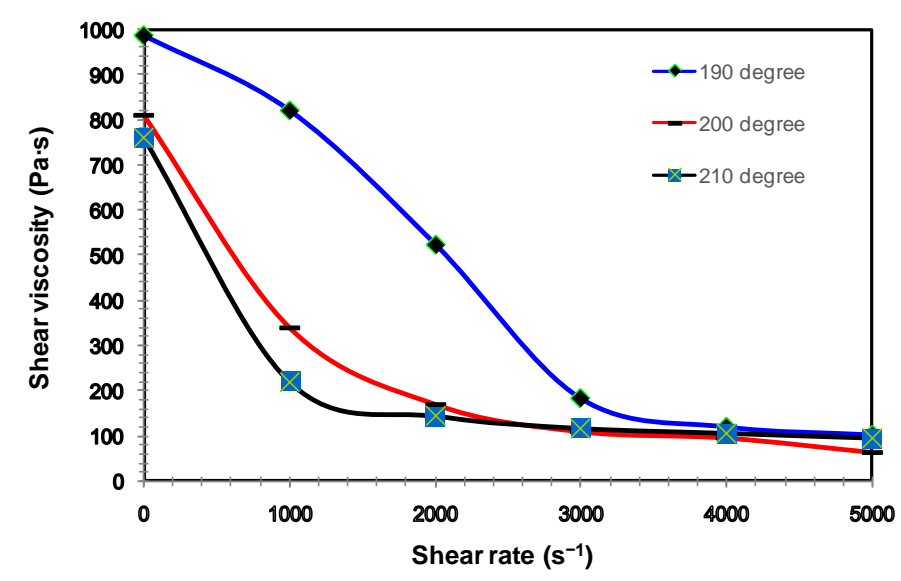

Figure 2. Variation of the viscosity with a function of shear rate of HYP/PA11 at various temperatures. 


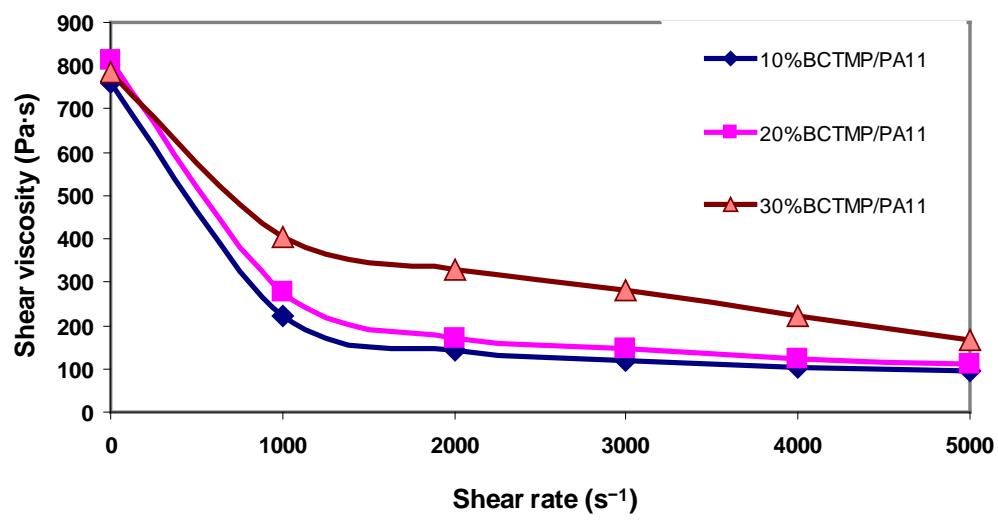

Figure 3. Shear viscosity vs. shear rate of HYP/PA11 at $200^{\circ} \mathrm{C}$.

fibre content, random anisotropic structures of the fibres in polymer melts are created. The increase in shear viscosity is found to be more predominant at lower shear rates, where fibre and polymer molecules are not completely oriented.

\subsection{Effect of High-Yield-Pulpfibre Aspect Ratio on Rheological Properties}

The results from the study of the effect of the aspect ratio of flexible-pulp-fibre-reinforced bio-based nylon 11 are presented below in Figure 4.

At low fibre aspect ratio, the decrease in viscosity as a function of the shear rate is greater for both low and high shear rate. Contrarily, at higher fibre-aspect ratio the shear viscosity shows a moderate decrease for low and intermediate shear rate.

At low and intermediate shear rate, the viscosity curves are slightly decreased and the distance between each viscosity curve remains large. However, at high shear rate the viscosity plots are tightly close. This is because fibre agglomeration and entanglement are not pronounced at high shear rate or frequency, due to the complete orientation of the fibre and polymer molecules. Much as with high fibre content, the increase in shear viscosity is found to be greater at lower shear rates, where fibre and polymer molecules are not completely oriented.

\subsection{Scanning Electron Microscopy}

Fracture surfaces of the extrudate of HYP/PA11 composite were examined using SEM. No fibre pullout was observed. The chemical structures of polyamide and wood fibre both include a hydrogen bond, which makes for better compatibility between high-yield pulp and polyamide. Figure 5 represents the SEM micrograph of HYP/ PA11 composite.

This micrograph indicated efficient bonding between the high-yield fibre and bio-based nylon. The experimental and predicted data fit very well, which meant that there was strong adhesion at their interface due to the presence of the third phase.

\section{Conclusion}

This study demonstrates that it is possible to extrudate natural fibre with high-thermoplastic-engineering biobased nylon. Fibre distribution after processing has been characterized by FQA for high-yield fibre in composites containing $10 \%, 20 \%$ and $30 \%$ fibres. The low-temperature-process compounding presents higher shear viscosity than the high-temperature processing of HYP/PA11 for the same rheological parameters. This is because during the process the temperature was low and the mixing and melting processes were generated by the high shear rate created during extrusion. Experimental test results of HYP/PA11 for both processing parameters show a steep decrease in shear viscosity with increasing shear rate, and this melt-flow characteristic corresponds to shear thinning behavior in HYP/PA11. Experimental results showed high shear-thinning behavior in HYP/PA11 associated with a high degree of pseudoplasticity; this was due to the good dispersion of high-yield pulp fibre into Nylon11 and the orientation of the flexible pulp fibre in the direction of the molten PA11. Finally, the morphological properties of HYP/PA11 composite were examined using scanning electron microscopy (SEM). Due 


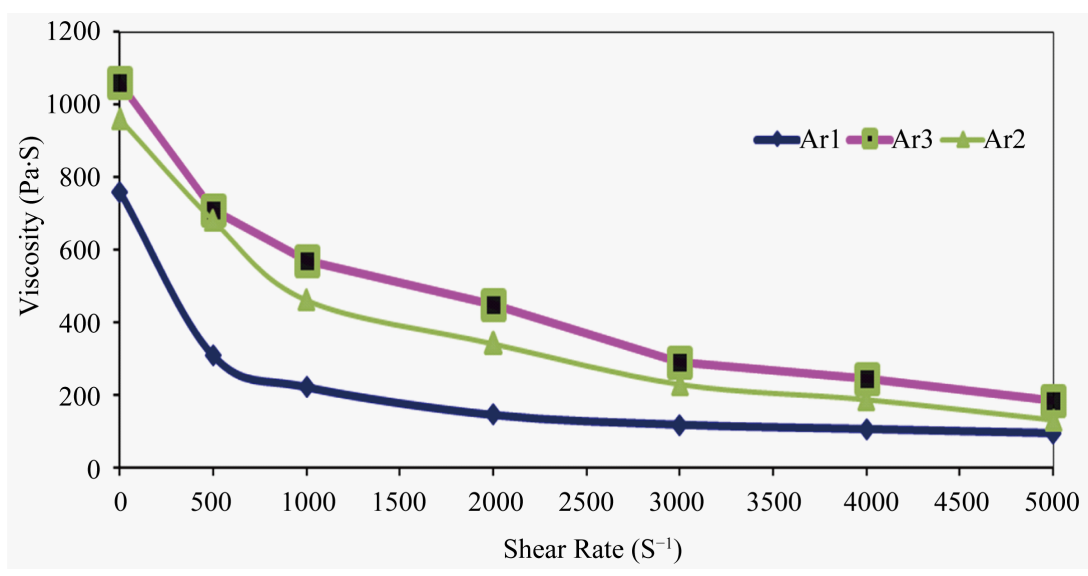

Figure 4. Shear viscosity vs. shear rate of HYP/PA11 at $200^{\circ} \mathrm{C}$.

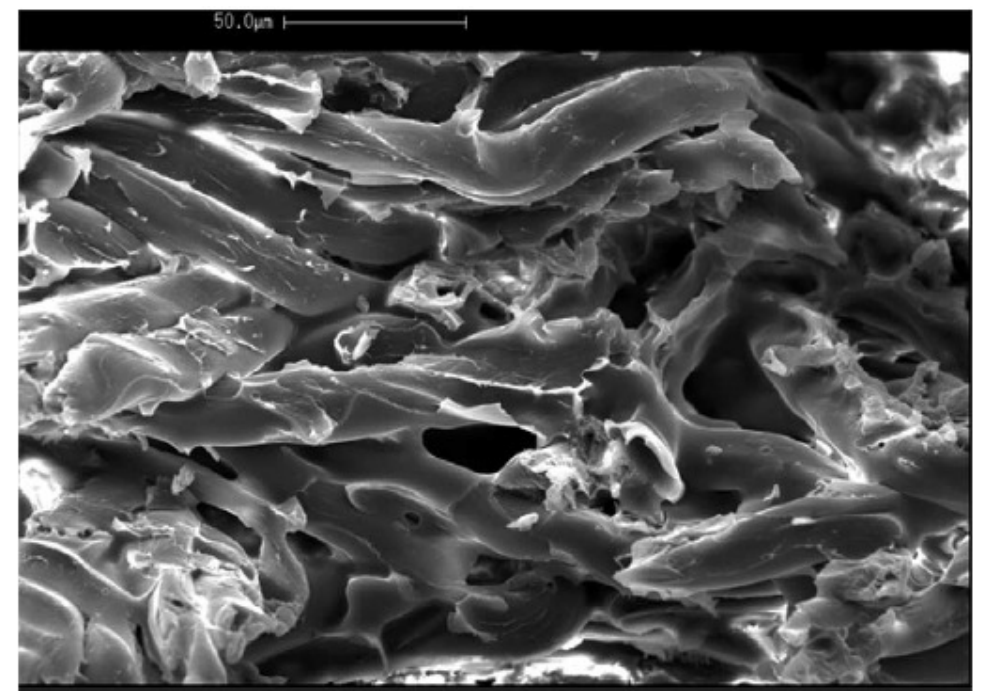

Figure 5. An SEM micrograph of pulp-fibre-reinforced polyamide composite fracture surface showing partially melted nylon fibre.

to the presence of the hydrogen bond, no fibre pullout was observed and there was good adhesion between highyield pulp fibre and polyamide.

\section{Acknowledgements}

This work was carried out with the support of Mitacs funding; the University of Toronto and the Ford Motor Company financially supported this study.

\section{References}

[1] Pervaiz, M. and Sain, M. (2003) Carbon Storage Potential in Natural Fibre Composites. Resources, Conservation and Recycling, 39, 325-340. http://dx.doi.org/10.1016/S0921-3449(02)00173-8

[2] Bourmaud, A. and Baley, C. (2009) Rigidity Analysis of Polypropylene/Vegetal Fibre Composites after Recycling. Polymer Degradation and Stability, 39, 297-305. http://dx.doi.org/10.1016/j.polymdegradstab.2008.12.010

[3] Duc, A., Vergnes, B. and Budtova, T. (2011) Polypropylene/Natural Fibres Composites: Analysis of Fibre Dimensions after Compounding and Observations of Fibre Rupture by Rheo-Optics. Composites Part A: Applied Science and Manufacturing, 42, 1727-1737. http://dx.doi.org/10.1016/j.compositesa.2011.07.027

[4] Ayroud, A.M. (1985) High Yield and Very High Yield Pulping. Pulp \& Paper Manufacture. Sulfite Science \& Technology, Joint Textbook Committee, CPPA/TAPPI, Vol. 4, 135-159. 
[5] Thumm, A. and Dickson, A. (2013) The Influence of Fibre Length and Damage on the Mechanical Performance of Polypropylene/Wood Pulp Composites. Composites Part A: Applied Science and Manufacturing, 46, 45-52. http://dx.doi.org/10.1016/j.compositesa.2012.10.009

[6] Sadeghian, N. and Golzar, M. (2008) PVT Measurement System for Wood Plastic Composite Melt in an Extrusion Process. Journal of Reinforced Plastics and Composites, 27, 739-750. http://dx.doi.org/10.1177/0731684407084250

[7] Thomen, H. (2001) Modeling the Physical Processes in Natural Fiber Composites during Batch and Continuous Pressing. Thesis, Oregon State University, Corvallis.

[8] Gu, R. and Kokta, B. (2010) Mechanical Properties of PP Composites Reinforced with BCTMP Aspen Fiber. Journal of Reinforced Plastics and Composites, 23, 513-542.

[9] Technical Association of the Pulp and Paper Industry (2007) Forming Hand Sheets for Physical Tests of Pulp. TAPPI Test Methods. TAPPI, Norcross.

[10] Bajpai, P. (2012) Brief Description of the Pulp and Paper Making Process. Biotechnology for Pulp and Paper Processing, 7-14. http://dx.doi.org/10.1007/978-1-4614-1409-4_2

[11] Plackett, D., Torgilsson, R. and Andersen, T. (2010) Influence of Fiber Type, Fiber Mat Orientation, and Process Time on the Properties of a Wood Fiber/Polymer Composite. International Journal of Polymeric Materials, 51, 1005-1018. http://dx.doi.org/10.1080/714975684

[12] Kaw, A. and Besterfield, G. (1998) Effect of Interphase on Mechanical Behavior of Composites. Journal of Engineering Mechanics, 117, 2641-2658. http://dx.doi.org/10.1061/(ASCE)0733-9399(1991)117:11(2641)

[13] Yeh, J.R. (1992) The Effect of Interphase on the Transverse Properties of Composites. International Journal of Solids and Structures, 29, 2493-2502. http://dx.doi.org/10.1016/0020-7683(92)90005-E

[14] Gohil, P. and Shaikh, A. (2010) Analytical Investigation and Comparative Assessment of Interphase Influence on Elastic Behavior of Fiber Reinforced Composites. Journal of Reinforced Plastics and Composites, 29, 685-699.

[15] Kari, S., Berger, H., Rodriguez, R.R. and Gabbert, U. (2005) Computational Evaluation of Effective Material Properties of Composites Reinforced by Randomly Distributed Spherical Particles. Composite Structures, 71, 397-400.

[16] Lamnawar, K. and Maazouz, A. (2008) Rheology at the Interface and the Role of the Interphase in Reactive Functionalized Multilayer Polymers in Coextrusion Process. American Institute of Physics, 978, 7354-7549.

[17] Larache, M., Agbossou, A. and Pastor, J. (1994) Role of Interphase on Elastic Behavior of Composite Materials: Theoretical and Experimental Analysis. Journal of Composite Materials, 28, 1141-1157.

[18] George, J., Sreekala, M.S. and Thomas, S. (2001) A Review of Interface Modification and Characterization of Natural Fiber Reinforced Plastic Composites. Polymer Engineering Science, 41, 1471-1485. http://dx.doi.org/10.1002/pen.10846

[19] Liu, Y.J., Xu, N. and Luo, J.F. (2000) Modeling of Interphases in Fiber-Reinforced Composites under Transverse Loading Using Boundary Element Method. Journal of Applied Mechanics, 67, 41. http://dx.doi.org/10.1115/1.321150

[20] Uhlherr, P.H.T., Guo, J., Zhang, X.M., Zhou, J.Z.Q. and Tiu, C. (2005) The Shear-Induced Solid-Liquid Transition in Yield Stress Materials with Chemically Different Structures. Journal of Non-Newtonian Fluid Mechanics, 125, 101119. http://dx.doi.org/10.1016/j.jnnfm.2004.09.009

[21] Huq, A.M.R. and Azaiez, J. (2005) Effect of Length Distribution on the Steady Shear Viscosity of Semi-Concentrated Polymer-Fiber Suspensions. Polymer Engineering \& Science.

[22] Sepehr, M., Ausias, G. and Carreau, P. (2004) Rheological Properties of Short Fiber Filled Polypropylene in Transient Shear Flow. Journal of Non-Newtonian Fluid Mechanics, 123, 19-32. http://dx.doi.org/10.1016/j.jnnfm.2004.06.005

[23] Eberle, A., Baird, D., Wapperom, P. and Vélez-García, G. (2009) Obtaining Reliable Transient Rheological Data on Concentrated Short Fiber Suspensions Using a Rotational Rheometer. Journal of Rheology, 53, 1049-1068. http://dx.doi.org/10.1122/1.3177348

[24] Larson, R.G. (1999) The Structure and Rheology of Complex Fluids. Oxford University Press, New York.

[25] Eberle, A.P.R. (2008) The Dynamic Behavior of a Concentrated Composite Fluid Containing Non-Brownian Glass Fibers in Rheometrical Flows. Ph.D. Thesis, Virginia Tech, Blacksburg.

[26] Le Moine, N., van den Oever, M. and Budtova, T. (2013) Dynamic and Capillary Shear Rheology of Natural FiberReinforced Composites. Polymer Engineering \& Science, 53, 2582-2593.

[27] Guo, R., Azaiez, J. and Bellehumeur, C. (2005) Rheology of Fiber Filler Polymer Melts: Role of Fiber-Fiber Interactions and Polymer-Fiber Coupling. Polymer Engineering \& Science, 45, 385-399.

[28] Le Moine, N., van den Oever, M. and Budtova, T. (2011) A Statistical Analysis of Fibre Size and Shape Distribution after Compounding in Composites Reinforced by Natural Fibres. Composites Part A: Applied Science and Manufacturing, 42, 1542-1550. http://dx.doi.org/10.1016/j.compositesa.2011.07.012 
Scientific Research Publishing (SCIRP) is one of the largest Open Access journal publishers. It is currently publishing more than 200 open access, online, peer-reviewed journals covering a wide range of academic disciplines. SCIRP serves the worldwide academic communities and contributes to the progress and application of science with its publication.

Other selected journals from SCIRP are listed as below. Submit your manuscript to us via either submit@scirp.org or Online Submission Portal.
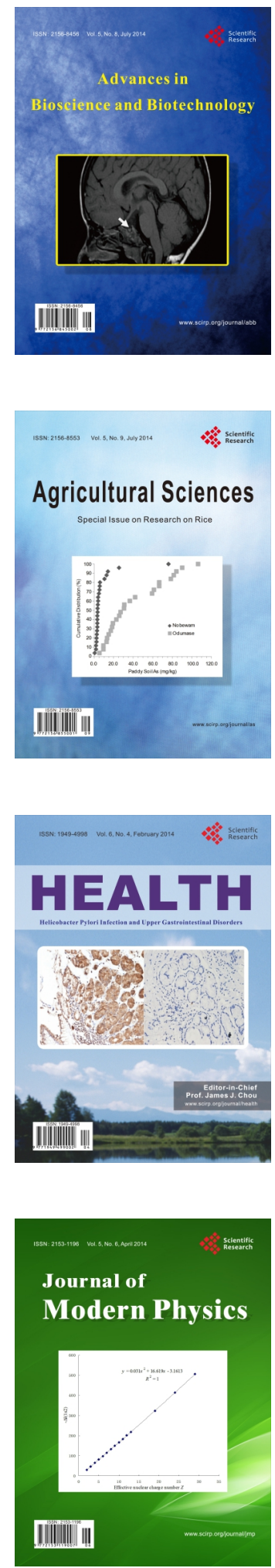
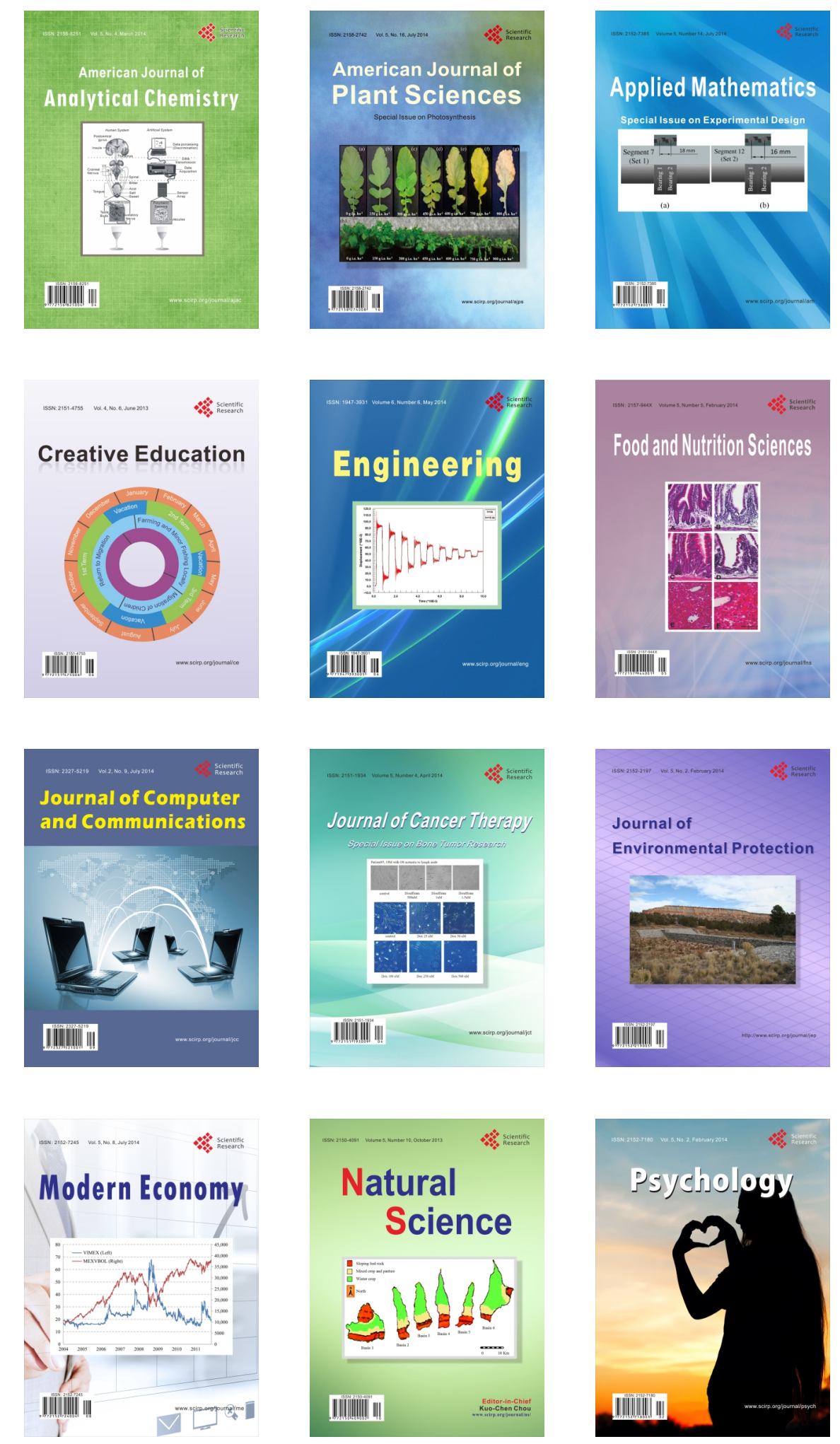